\title{
ECOLOGIA E MODERNIDADE EM Os Parceiros do Rio Bonito de Antonio Candido: UMA PRIMEIRA APROXIMAÇÃO
}

\section{Ana Carolina Vila Ramos dos Santos ${ }^{1}$}

\begin{abstract}
Resumo
Nesse trabalho, proponho uma leitura peculiar acerca dos dilemas da modernidade brasileira a partir da obra "Os Parceiros do Rio Bonito" de Antonio Candido. Tomando como partida uma sociologia da questão ambiental brasileira, focalizase 0 entrelaçamento entre 0 tema da natureza e da modernidade e se sugere que Antonio Candido, ao aproximar-se das proposições de Sérgio Buarque de Holanda em "Caminhos e Fronteiras" e "Monções", propõe uma leitura muito original acerca da modernidade brasileira que se aproxima do que a sociologia internacional intitula "modernidades múltiplas" (EISENSTAEDT, 2000; WITTROCK, 2000; TAVOLARO, 2005).
\end{abstract}

Palavras-chave: Natureza. Modernidade brasileira. Sociologia ambiental.

\footnotetext{
${ }^{1}$ Mestre e Doutoranda em Sociologia - UNICAMP. End. Eletrônico: carol_vrs@yahoo.com.br
} 


\title{
ECOLOGY AND MODERNITY IN ANTONIO CANDIDO's “Os PARCEIROS DO RIO BONITO”: A FIRST APPROACH
}

\begin{abstract}
In the present study, I propose a peculiar outlook on the Brazilian modernity dilemma, through Antonio Candido's book, "Os Parceiros do Rio Bonito". Taking the sociology of the Brazilian environmental issue as the starting point, the study focuses on the encounters between nature and modernity and suggests that Antonio Candido, approaching Sergio Buarque de Holanda's propositions exposed in "Monções"(1945) and "Caminhos e Fronteiras" (1957), offers a unique interpretation concerning the Brazilian modernity, which is similar to what international literature has called "multiple modernities" (EISENSTAEDT, 2000; WITTROCK, 2000; TAVOLARO, 2005)
\end{abstract}

Keywords: Nature. Brazilian modernity. Environmental sociology

\section{INTRODUÇÃO}

$\mathrm{E}$

sta leitura da obra de Antonio Candido toma como impulso essencial o estudo sobre a recepção, institucionalização e consolidação dos estudos acerca das relações entre ambiente e sociedade, registradas na história da sociologia. Seguindo os passos do que Leila Ferreira chama de sociologia da sociologia ambiental, este trabalho é fruto de um longo estudo, ainda em curso, acerca do que se pensou sobre natureza e sociedade na história da sociologia brasileira em seus primeiros momentos. A "sociologia da sociologia ambiental" que proponho, inspirada na proposta de Leila C. Ferreira (2006), pode ser tomada como uma incursão na história da sociologia por meio da qual intenta-se: a) recuperar o modo pelo qual se pensou as relações entre natureza e sociedade; $b$ ) investigar o lugar da temática na produção do período, e, finalmente, c) apontar as peculiaridades dessas primeiras leituras da sociologia brasileira sobre as relações entre natureza e sociedade na produção sociológica subseqüente.

As posturas da sociologia em seus primeiros passos no interior da temática ambiental poderiam, a meu ver, ser divididas em duas: uma convicção de inexpressividade e desinteresse pelo tema, de um lado, e o fascínio diante do novo, por outro lado, como se a urgência da crise ambiental apagasse tudo o que já se havia pensado sobre natureza e sociedade. Sociologia e ambiente/sociedade 
pareciam termos quase irreconciliáveis nessas primeiras impressões da sociologia acerca da temática ambiental.

0 pathos pela urgência da crise ambiental, que se afigura no início da década de 1970, é uma sensação que sempre esteve à espreita nos estudos sobre ambiente e sociedade. A crescente degradação ambiental teimava em apontar uma defasagem entre a realidade (a crise aguda das relações da sociedade com a natureza) e o pensamento (o desinteresse e mesmo a incapacidade do pensamento ocidental em entender e propor "soluções" para a crise). A crescente percepção da degradação ambiental como um problema social e o número cada vez maior de análises acerca dos movimentos ambientalistas surgem, no interior da sociologia, em um contexto de mais uma "crise" da disciplina.

Para um número crescente de sociólogos dedicados ao estudo das relações ambiente e sociedade, a sociologia parecia não dar mais conta de compreender e explicar o mundo que se fazia: novas teorias, novos métodos, modos distintos e originais de olhar o mundo precisavam ser elaborados para dar conta da nova configuração do real. 0 projeto intelectual que desenvolvo neste trabalho inverte os termos da questão: tomo esta novidade da temática ambiental como ponto de vista na leitura de obras clássicas do pensamento sociológico brasileiro. Parto da contemporaneidade rumo à história do pensamento.

Ao recuperar a história das reflexões sobre natureza e sociedade, proponho um olhar diferenciado de obras importantes à formação do pensamento sociológico brasileiro, trazendo à luz um tema "quase esquecido" dos estudos contemporâneos sobre a história das ciências sociais brasileiras. Tema "quase esquecido", mas que tem centralidade em obras formadoras do campo sociológico do país que discutem um tema caro à sociologia contemporânea, a modernidade.

A natureza, até a década de 1930, tinha uma presença importante no debate sobre nação e nacionalidade. A partir da década de 1940, natureza é como que "enquistada" no mundo rural, este tomado como resquício do privatismo e do aristocratismo dos tempos do Império e da República Velha. Passado a ser superado.

De 1940 an final da década de 1970, natureza é obstáculo ao progresso material do país. As relações dos homens com a natureza voltam à cena quando dos primeiros questionamentos do nascente ambientalismo brasileiro - voltam à cena, mas premidas de uma significação completamente distinta daquela da década de 1930. A natureza é tema da disputa política - há a percepção de que 
os usos da natureza são foco de conflitos políticos, econômicos e sociais, cujo coroamento é o êxito nos debates que deram forma à Constituição de 1988.

$\mathrm{Na}$ proposta de pesquisa que elaborei, penso exatamente esse período de desvanecimento da idéia de natureza. "Os Parceiros do Rio Bonito", sugiro, encontra-se na confluência de debates importantíssimos acerca de concepções de sociedade, cultura e natureza, travados entre propostas metodológicas e teóricas tão distintas quanto a miríade de propostas agrupadas sob a rubrica "estudos de comunidade" e os trabalhos de Sérgio Buarque de Holanda. Tanto os "estudos de comunidade" quanto a análises de Sérgio Buarque têm um forte impacto na produção uspiana das décadas de 1950 e 1960. Penso que as reflexões sociológicas de Antonio Candido em "Os Parceiros do Rio Bonito" são em muito tributárias, como o próprio autor reconhece, às reflexões de Sérgio Buarque de Holanda desenvolvidas em seus trabalhos sobre a conquista do Oeste brasileiro, bem como representam uma leitura muito crítica ao mundo rural tal como concebido nos "estudos de comunidades", em voga na década de 1940. Ainda que de forma embrionária, natureza e seu entrelaçamento com o tema da modernidade será nosso guia na leitura que propomos da obra de Antonio Candido.

\section{O Pensamento social e o tema da natureza}

Natureza é um tema inextricável de cultura e sociedade. 0 pensamento social brasileiro nos mostra isso de forma magistral - os diferentes matizes da idéia de natureza dão conta das diversas nuances dos temas culturais e sociais dos quais os autores se ocupam em sua história. Desde o movimento romântico, a natureza esteve às voltas com o que se pensou sobre a Nação. É no pensamento romântico brasileiro que a natureza tropical assume um caráter ativo e positivo na conformação da nacionalidade.

Nos romances regionalistas de meados do século XIX, encontraremos a exaltação à natureza como forma de exercício do patriotismo. 0 apego à realidade, a descrição objetiva do cotidiano e da vida social se apresentam como contrapesos ao individualismo e ao lirismo, tão peculiares ao romantismo europeu. Dar a conhecer seu país se constituía na grande missão do romântico brasileiro. A natureza, nos romances regionalistas, é um aspecto do mundo exterior, concreto, palpável, objeto de uma detalhada descrição e estudo que parece convidar o leitor a encarar o país de um ponto de vista renovado: de quem conhece e, mais do que isso, de quem o admira. 0 importante a apreender do sentido que a idéia de 
natureza toma no regionalismo brasileiro, desse período, é que a natureza deixa de ser espaço de contemplação nativista para se tornar liame que dá coesão e sentido às matrizes étnicas e culturais, aqui aportadas nos primeiros séculos da formação nacional do país.

Nesse processo de "auto-definição da consciência local" (CANDIDO, 1975, p. 104), a geração de 1870 dá suas contribuições: levando à frente a crítica nacionalista romântica, Silvio Romero apresenta ao país a renovação intelectual do Naturalismo cuja desembocadura é "Os Sertões" (1902), de Euclydes da Cunha. A ciência vem em socorro da literatura nos novos diagnósticos da brasilidade; 'natureza', bem ao gosto do cientificismo então triunfante, recebe um sentido renovado; a natureza romântica se enrijece no determinismo da idéia de "meio" - a natureza é obstáculo ao progresso moral e material.

Se a natureza tropical e a miscigenação são os signos do atraso brasileiro, a missão desses "homens de sciencia" é explicar o atraso e apontar um futuro, 0 Brasil como nação. "Meio" e "raça", como conceitos operacionais dessas releituras, dão a medida da peculiaridade da realidade brasileira e apontam o futuro da nação na medida em que apostam na nação como projeto, consecução do longo processo evolutivo cujas conquistas - a natureza domada e o branqueamento do povo - são ideais a serem alcançados no futuro.

Nas primeiras décadas do século XX, a literatura regionalista nos apresenta outra concepção de cultura, sociedade e natureza, um projeto renovado de Nação. A natureza no regionalismo brasileiro, das décadas de 1920 e 1930, tem seu caráter determinista amenizado (fomentado em finais do século XIX) - a natureza é "paisagem" na medida em que é tomada como relíquia, memória viva da formação da Nação². A paisagem entendida como natureza socialmente construída é depositária de valores, de uma tradição, e é, portanto, uma "janela" à compreensão da cultura que a domesticou e humanizou: a paisagem é a cultura materializada, registro do humano na matéria física.

Gilberto Freyre, em suas renovadoras obras da década de 1930, tem um forte diálogo com toda essa produção precedente: a despeito de sua crítica ao viés racista e determinista da produção intelectual brasileira das últimas décadas do

\footnotetext{
${ }^{2}$ Não quero com essa "classificação" sugerir que a cada grupo de autores e obras se atribui um único sentido de natureza, ou seja, por meio desses recortes, intento perceber a predominância de um certo sentido em um grupo de autores e obras sem me esquecer da convivência e "disputas" dos sentidos de natureza em cada recorte histórico.
} 
século XIX, sua história da formação do patriarcado brasileiro guarda um forte diálogo com a produção precedente. A idéia de "trópico" é um bom guia na compreensão desse diálogo. Entre duas tradições, a literatura e a ciência, Freyre toma "trópico" como elemento de equilíbrio entre "raça" e "cultura". Freyre não abandona por completo o debate determinista; ele promove uma releitura da produção anterior do ponto de vista das propostas sociológicas, antropológicas e históricas que conhecera como estudante de ciências humanas, em uma longa estadia no exterior (EUA e Europa). Entre "meio" e "paisagem", determinismo e "livre-arbítrio", Freyre equilibra duas tradições do pensamento social brasileiro, a ciência e a literatura (CANDIDO, 2000), dá forma a uma interpretação extremamente original do passado do país e aponta caminhos na construção de um projeto sui generis de modernidade nos trópicos.

Até 1930, poderia arriscar uma síntese: o pensamento social brasileiro tinha a questão nacional como tração essencial de suas reflexões. A natureza nessa ambiência de idéias é parte importante do que se pensa e entende por brasilidade.

Como propõe Tavolaro (2005; 2008), o pensamento social brasileiro, desde suas origens, produziu imagens a respeito da modernidade e da relação sociedade/ natureza no Brasil, tomando como gabarito uma determinada construção teórica acerca da modernidade, ancorada no que o autor chama de "discurso sociológico

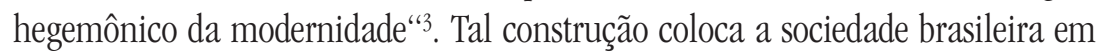
uma situação desigual com relação ao centro dinâmico da modernidade: 0 atraso ou o exotismo da sociedade brasileira, denotados pela suposta especificidade da relação sociedade/natureza no país, mostra-se como prova irrefutável da distância entre Brasil e o núcleo da modernidade.

As reflexões de Freyre, assim como das gerações de intelectuais que 0 precedeu, dão conta dessa centralidade do tema natureza, em seus mais diversos sentidos, na conformação da Nação Moderna. Na década de 1940, contudo, a natureza parece sair do palco da reflexão social: novos problemas acionam as

\footnotetext{
3 Tavolaro (2008) nos traz de forma clara o que chamamos de episteme da modernidade, sintetizado em quatro elementos: a diferenciação ou complexificação social das esferas sociais, de modo que cada uma delas assume uma lógica própria; a secularização ou des-tradicionalização das esferas sociais ou "desencantamento do mundo" em uma acepção weberiana; a separação entre os âmbitos público e o privado, vinculada a um processo intenso de individuação e a radical separação entre natureza e sociedade, levada a cabo pela modernidade. Essa episteme tem em Marx, Weber, Durkheim, Simmel e seus herdeiros Parsons, Habermas, Bourdieu e Giddens, seus grandes representantes.
} 
mentes de nossos intelectuais. Nação, raça e meio parecem não mais dar conta da avalanche de novidades da qual o país é tomado na década de 1940. A modernidade brasileira passa a ser pensada sobre outros patamares.

\section{NATUREZA PARA PENSAR MODERNIDADE}

Na década de 1940 se aprofundam, na sociedade brasileira, as contradições econômicas, sociais e políticas gestadas pela economia agro-exportadora. É também nesse período que entra em crise o poder da aristocracia rural apoiada, desde meados do século XIX, na monocultura do café; a produção industrial toma corpo nessa década com o crescente investimento estrangeiro e as grandes cidades começam a se abarrotar de gente. Este período é de grande turbulência política - lembremo-nos somente de um acontecimento marcante: o fim da ditadura getulista em 1945.

A primeira metade do século XX tem também importância ímpar na institucionalização e consolidação da sociologia como disciplina científica. Já em fins da década de 1930, os primeiros trabalhos propriamente sociológicos começam a tomar forma na FFCL da Universidade de São Paulo e na Escola Livre de Sociologia e Política; em fins da década de 1940, há mesmo uma produção expressiva partindo desses núcleos paulistas.

Para pensarmos natureza e modernidade em Antonio Candido, focalizo dois grupos de autores e obras que tiveram grande peso nas formulações de Candido em seu "Parceiros do Rio Bonito" (1954): os estudos de comunidade, levados a cabo por Donald Pierson e Emilio Willems à frente, especialmente, da Escola Livre de Sociologia e Política de São Paulo; e as obras de Sérgio Buarque de Holanda sobre a conquista do Oeste "Monções" "e "Caminhos e Fronteiras". Sugiro que Antonio Candido e sua obra se encontram na confluência desses dois grupos de produções e que sua crítica aos "estudos de comunidade" é ponto de partida de seu "ecletismo" teórico-metodológico. Sua aproximação com Sérgio Buarque de Holanda, em especial de seus estudos sobre a ocupação do Oeste brasileiro, por outro lado, é enfaticamente lembrada ao longo da obra. A relação do caipira com o meio é pedra de toque da história do caipira que Antonio Candido refaz em sua bela obra.

Tratemos de forma sucinta desse primeiro grupo de obras e autores: os estudos de comunidade. Como reconhece Ianni (1989), o conhecimento científico 
da realidade brasileira das décadas de 1940 e 1950 muito deve aos esforços levados a cabo nesses estudos. Como uma reação ao ensaísmo, nada rigoroso da década de 1930, este tipo de orientação teórico-metodológica, inspirada principalmente na sociologia americana das primeiras décadas do século XX, responde muito bem aos clamores de um estudo sistemático e rigoroso da tão pouco conhecida realidade brasileira. 0 "estudo de comunidade", como recurso de estudo sistemático da realidade, permite a conjugação de pesquisas de reconstrução histórica às de campo, assim como a associação das técnicas de observação qualitativas à inquirição estatística. No quadro do ensaísmo, que tão bem caracteriza a produção intelectual brasileira desde o Romantismo (CANDIDO, 2000), a conciliação entre propostas metodológicas das ciências do espírito e das ciências naturais pareceu uma saída ao caos impressionista ao que o pensamento e a ação estavam condenados no país.

Nas décadas de 1940 e 1950, é produzida uma enxurrada de estudos de comunidade, de uma riqueza teórica e metodológica incrível. Dois grandes autores se destacam em meio a tal produção: Donald Pierson e Emílio Willems. De forma geral (que seguramente encerra um grau de reducionismo que espero sanar com 0 decorrer da pesquisa), esses professores, à frente da Escola de Sociologia e Política de São Paulo, e os trabalhos de seus orientandos, produzidos nas décadas de 1940 e 1950, têm como tração essencial explicar a transição do rural para o urbano, da tradição à modernidade, tomando como recorte metodológico pequenas comunidades, situadas em áreas de avanço da urbanização.

Não podemos deixar de lado o caráter eminentemente prático do qual se emanaram esses trabalhos: oferecer aos administradores públicos dados objetivos e seguros para o planejamento de políticas de atenção às comunidades desgarradas da onda de progresso e modernidade foi, certamente, um impulso de monta na elaboração e publicação desse tipo de pesquisa. Como atenta Ianni (1989), não se tratava apenas de conhecer a realidade, mas de agir sobre ela de forma eficiente.

A despeito de suas contribuições ao conhecimento da realidade do país; a despeito de sua larga aceitação como diagnóstico confiável e guia da ação política, os "estudos de comunidades" pareciam ter sérias limitações na análise social bem como na condução da ação política. Antonio Candido (2001), Florestan Fernandes (1977) e Otavio Ianni (1989), grandes nomes da chamada sociologia crítica uspiana, apresentam reparos argutos às propostas teóricas e metodológicas presentes nesses estudos. 
Como observa Florestan Fernandes (1977), as análises desenvolvidas estão limitadas à caracterização empírica do funcionamento atual da estrutura social. Isto é, ao confundirem "solução metodológica" com "alternativa teórica" (IANNI, 1989), esses estudiosos se centraram na comunidade como se fosse possível extrair de lá os mecanismos fundamentais das transformações estruturais que ocorriam no Brasil de então. A reflexão deixou de lado processos mais amplos e profundos implicados no processo de transição dos modos de vida rural-urbano, de modo a comprometer o alcance explicativo da pesquisa. Dito de outra forma, tais trabalhos não explicam a transição rural-urbano, pois estão restritos ao diagnóstico do presente, presos ao rigorismo dos fatos e da metodologia, atentos à demanda dos administradores públicos ávidos por modernizarem seu país. 0 rural, do ponto de vista daqueles que produziram dezenas de "estudos de comunidade", era sinônimo de atraso e um mundo fadado ao desaparecimento. Tais estudos tinham por objetivo pensar formas de transição da tradição para o moderno, como esclarece Ianni (1989). É a partir desses reparos, acredito, que Antonio Candido pensa a cultura caipira em sua bela obra objeto de estudo deste artigo $0^{4}$.

Empunhando a bandeira de uma sociologia crítica, tais autores, em especial Antonio Candido no que toca ao tema natureza, entram na disputa pelo sentido de sociologia que deveria ser adotado e praticado. Condenavam-se a falta de rigor científico do ensaísmo, que tão bem caracterizou o pensamento social brasileiro desde sua origem, esses autores estavam atentos ao tipo de ciência produzida sob a rubrica "estudos de comunidade".

De um ponto de vista bem distante daquele adotado pelos "estudos de comunidade" e aproximando-se da sociologia crítica uspiana, Sérgio Buarque de Holanda, nas obras nas quais analisa o povoamento do Centro-Sul e Oeste do país - "Monções" (1945) e "Caminhos e Fronteiras" (1957) - olha para a "dialética entre as persistências e as mudanças" (DIAS, 1985), entre o tradicional e 0 moderno, na releitura que faz da "epopéia bandeirante".

A partir de uma leitura crítica de toda a historiografia paulista produzida desde as últimas décadas do século XIX, que Ferreira (2002) cunha de "epopéia

\footnotetext{
${ }^{4}$ É interessante notar as implicações que a nomenclatura "estudos de comunidade" utilizada por Candido (2001), Fernandes (1977) e Ianni (1989) traz em si; uma delas já podemos perceber: o termo largamente utilizado pelos autores faz tabula rasa de uma produção teórico-metodológica riquíssima que abarca uma miríade de autores e trabalhos. A rubrica, portanto, denota menos essa riqueza teórico-metodológica que uma certa leitura desses autores acerca desse imenso grupo de estudos.
} 
bandeirante", somada a ricas fontes e frutíferos debates propostos pela historiografia americana e a sociologia alemã e francesa, Sérgio Buarque entrevê a transição para o moderno sob a ótica dos que sempre estiveram fora dos centros de poder, que não contavam na historiografia oficial, os mateiros, os monçoneiros, os pescadores, os caçadores. É do ponto de vista do homem simples, de sua luta cotidiana com o meio, de seu trato com o outro que Sérgio Buarque pensa tradição e modernidade como pares de uma dialética que se repõem ao longo de toda a história da ocupação do planalto paulista.

"Monções" (1945) e "Caminhos e Fronteiras" (1957) alinham-se à "primeira fase da pesquisa sistemática das fontes" da produção historiográfica do autor, como sugere Dias (1985). "Caminhos e Fronteiras", publicado em 1957, reúne textos produzidos desde o final da década de 1940, inclusive o importante "Índios e Mamelucos na expansão paulista", publicado em 1949, que tão forte impacto causou nas reflexões de Antonio Candido quando de sua análise do caipira, exposta em "Os Parceiros do Rio Bonito" 5.

Nessa série de estudos, Sérgio Buarque trata do processo de ocupação do planalto paulista rumo ao Centro-Oeste brasileiro, realizado nos séculos XVII e XVIII pelas bandeiras. Em "Monções", o autor trata de um período posterior às bandeiras, fins do século XVIII e início do XIX. Nesse período, não mais a "aventura", o jogar-se no sertão em busca de terras e riquezas (mentalidade que comandou 0 desbravamento do sertão paulista em suas primeiras investidas), comandava as expedições: as monções assinalam o fomento gradual de uma mentalidade que preza pela estabilidade. Embora um sentido de "aventura" ainda persista, uma série de indícios, reconstruídos por Sérgio Buarque, apontam para o progressivo apego à terra. Para comercializar com aqueles já assentados na "fronteira", essas expedições fluviais tiveram como corolário a ocupação e o povoamento do sertão.

Nessas obras, sociedade, cultura e natureza são pensadas em suas interrelações de modo que as relações dos homens com a natureza são tratadas de forma indissociável das relações que os homens mantém entre si. É na "fronteira" e não no litoral, argumenta Sérgio Buarque repondo os termos do debate sobre os "Dois Brasis", que percorre toda história do pensamento social brasileiro (TRINDADE,

\footnotetext{
${ }^{5}$ Em prefácio à $1^{a}$ edição da obra "Caminhos e Fronteiras", Sérgio Buarque agradece enfaticamente a Antonio Candido "a primeira lembrança de uma possível coordenação dos estudos já parcialmente impressos que viriam a constituir o presente volume" (HOLANDA, 1994, p. 15) referência que denota que Antonio Candido há muito tempo conhecera os estudos de Holanda sobre a conquista do Oeste.
} 
1999); que uma relação entre homens (do português com o nativo) e destes com a natureza é paulatinamente construída de forma adequada às condições do meio e da gente e é também na "fronteira" que uma modernidade "brasileiríssima" é forjada.

As análises históricas, baseadas no estudo das práticas materiais, refletem o modo pelo qual a relação com a natureza se cristalizou às percepções, valores, leis e costumes dos homens - não é apenas o emprego de artimanhas diversas no enfrentamento das adversidades do meio que conta na forja de um "novo homem". Na "fronteira", trata-se acima de tudo, do advento de um complexo de atitudes e comportamentos que conformam uma mentalidade sui generis que tempera a tradição (o legado ibérico) com a novidade (o meio e a cultura nativa).

Wegner (2000), ao recuperar os diálogos de Holanda com a historiografia norte-americana da década de 1940, toma a "fronteira" como uma experiência sui generis na formação do ethos brasileiro. As relações entre homens e destes com a natureza em uma situação de "fronteira" é a chave compreensiva do modo pelo qual o autor requalifica, na experiência histórica brasileira, o "americanismo" em uma acepção um pouco distante daquela exposta em sua obra clássica "Raízes do Brasil" (1936), na qual expõe os elementos que nos contam da persistência da tradição, do legado ibérico.

Distanciando-se do que Jessé de Souza (2000) chama de "sociologia da inautenticidade", Sérgio Buarque de Holanda, em suas obras que tratam da conquista do Oeste, põe em suspensão as proposições pouco otimistas quanto à herança personalista que caracteriza a cultura brasileira, como argumenta em "Raízes do Brasil". Ao formular uma saída ao gabarito rígido da episteme da modernidade, que tão bem caracteriza a nossa "sociologia da inautenticidade" (SOUZA, 2000), Sérgio Buarque de Holanda abre um caminho original para pensar a modernidade brasileira como uma possibilidade construída a partir do programa cultural da modernidade.

\footnotetext{
${ }^{6}$ Para Jessé de Souza (2000) a "sociologia da inautenticidade" pode ser caracterizada como uma auto-interpretação acerca da modernidade brasileira por meio da qual tal idéia assume um sentido de superficialidade, de fachada, algo "para inglês ver". Sérgio Buarque de Holanda em seu "Raízes do Brasil", Raimundo Faoro e Roberto DaMatta são tomados como os grandes representantes dessa leitura sobre a modernidade brasileira. Embora Jessé de Souza trata a obra de Holanda com um corpo monolítico, neste proposta de pesquisa, parto da hipótese de uma reformulação da idéia de modernidade brasileira nas obras da maturidade de Sérgio Buarque.
} 
Ao antigo dilema da modernidade brasileira que angustiou gerações de intelectuais, Sérgio Buarque de Holanda pensa uma possível saída nas obras em que discute a experiência da "fronteira" na conformação da modernidade brasileira. Aproximando-se do que Eisenstadt (2000), Wittrock (2000) e Tavolaro (2005) chamam de "modernidades múltiplas", a "fronteira", nessas obras de Sérgio Buarque de Holanda, proporcionou dinâmicas fomentadas a partir do encontro de tradições e culturas que deram forma a uma "brasilidade", para o qual o projeto cultural da modernidade foi referência central, mas não o único e inescapável. 0 que interessa à condução desse trabalho é perceber como "natureza" assume centralidade no argumento de Sérgio Buarque, ao pensar - numa chave que se aproxima do modernismo - a originalidade da experiência moderna brasileira (WEGNER, 2000).

Tanto Sérgio Buarque de Holanda, em suas obras sobre a conquista do Oeste, quanto Candido apresentam uma leitura muito peculiar sobre natureza, atraso e modernidade. Esses autores resignificam o sentido de modernidade ao tomar o suposto atraso brasileiro como característica de uma modernidade peculiar - essa é a idéia à que gostaria de dar as primeiras formas nesse trabalho.

Fruto de um longo trabalho de campo (1948-54), realizado em pequenas comunidades rurais (os "bairros") localizadas no município de Bofete, Antonio Candido em "Os Parceiros do Rio Bonito", toma como objetivo conhecer os "meios de vida" do caipira. Para tanto, a relação que esse estabelece com a natureza tem centralidade na reflexão. Como esclarece o autor, "as sociedades se caracterizam, antes de mais nada, pela natureza das necessidades de seus grupos, e os recursos de que dispõem para satisfazê-las" (CANDID0, 2001, p. 29).

Assim, um equilíbrio, mesmo que relativo ou precário, entre as soluções concebidas para a satisfação das necessidades do grupo e os recursos da natureza é suposto da existência de todo grupo social. É a partir de uma "sociologia dos meios de subsistência" que Antonio Candido olha para o caipira; as relações que os caipiras estabelecem entre si e com a natureza com o objetivo de satisfazer uma necessidade física - a alimentação - são o foco da atenção do autor. Para tornar claro esse balanço precário entre natureza e sociedade, Antonio Candido nos apresenta os conceitos de "mínimos vitais" e "mínimos sociais".

Para cada sociedade, em um determinado momento, há um balanço imprescindível entre as necessidades dos grupos que a compõem e os recursos disponíveis para satisfazê-las, isto é, um ajuste entre organização social e meio. 
Esses ajustes manifestam soluções de equilíbrio do grupo: abaixo certos "mínimos vitais" de alimentação e abrigo, aos quais estão conjugados certos mínimos sociais de organização para obtê-los, não se tem uma situação de equilíbrio, mas sim fome e anomia (CANDIDO, 2001, p. 32-35).

A partir desse sutil e precário equilíbrio entre homens e destes com a natureza (entre os "mínimos vitais" e "mínimos sociais"), Antonio Candido recupera a história do caipira paulista, bem como percebe o sentido das mudanças econômicas e sociais que se avizinham com o avanço da agricultura comercial e a urbanização no século XX.

Antonio Candido descortina, nas palavras de Ianni (1989), o "homem simples" brasileiro ao nos contar da vida do caipira. 0 autor, ao romper com 0 excessivo empirismo dos "estudos de comunidades", toma a "auto-reflexão" do caipira (FRANCO, 1992) como uma reflexão que se amplia sobre a sociedade brasileira; ao captar o precário equilíbrio entre "mínimos vitais" e "mínimos sociais" naquela comunidade de caipiras em momento de grande transformação social, Antonio Candido apresenta uma crítica consistente ao suposto imobilismo das sociedades rústicas que ronda os "estudos de comunidades". 0 autor dá voz ao caipira, (personagem supostamente inexpressivo no Brasil Moderno), ao recuperar seu modo de vida, suas relações com os homens, sua relação com a natureza.

Em um movimento contrário ao desenvolvido pelos "estudos de comunidade", Antonio Candido olha para o caipira para pensar processos muitos mais amplos e profundos que presidem a modernização do país. Tal como Sérgio Buarque, o autor não supõe uma ruptura entre tradição e modernidade, pois pensa na convivência de temporalidades, na persistência de visões de mundo que, mesmo fadadas ao desaparecimento pela migração do homem do campo para os grandes centros urbanos ou pelo avanço da agricultura comercial, dão forma à consciência de amplas parcelas da população brasileira nas décadas de 1950 e 1960.

A questão que se coloca para Antonio Candido, a meu ver, é compreender o Brasil Moderno não como um desvio, uma versão imperfeita da modernidade ocidental, mas, como sugere Ortiz (1999, p. 165), "como uma diferença que não se esgota no atraso". Isso implica reconhecer uma originalidade no processo de constituição da modernidade brasileira, tal como sugere Eisenstadt (2000) quando pensa em "modernidades múltiplas", isto é, admitir diferenciadas e originais realizações históricas a partir de uma "matriz cultural moderna". 
Se o pensamento social brasileiro construiu projetos a respeito da modernidade e da relação sociedade/natureza no Brasil, tomando como gabarito o "discurso sociológico hegemônico da modernidade" e, portanto, patrocinou uma "sociologia da inautenticidade", como concebe Jessé de Souza (2000), as obras de Holanda sobre a conquista do Oeste e a sociologia de Antonio Candido tomam a modernidade brasileira, em especial a relação sociedade/natureza, de um ponto de vista muito distante. Proponho que a obra de Antonio Candido traz em si essa "novidade epistemológica" ao tomar a relação do caipira com a natureza como ponto de partida para pensar as possibilidades do Moderno no Brasil de meados do século XX.

Embora a "ecologia" desses autores (epor "ecologia" entendo, tão somente, as relações entre sociedade e natureza sem entrever qualquer tipo de orientação teórica ou metodológica) tenha sido deixada de lado pela literatura que trata da história do pensamento sociológico, as relações entre natureza e sociedade se articulam ao "coração" do pensamento dos autores escolhidos para esta análise. Essa era minha intenção na breve exposição que aqui fiz dos argumentos dos atores - recuperar, ainda que em caráter rudimentar e muito provisório (como uma primeira prospecção), o debate natureza e modernidade em um período crucial à formação do pensamento sociológico brasileiro.

A análise que proponho nasce no presente, em um esforço de recontar o que e como se pensaram as relações entre natureza e sociedade para melhor entender o que se pensa sobre natureza e sociedade hoje. Ainda que seja uma primeira aproximação, com todas as falhas que esta traz em si, a análise do modo como os sentidos da idéia de natureza se conformam em um período crucial à formação e institucionalização do pensamento sociológico brasileiro tem como intenção maior compreender as especificidades históricas desse período, compreender a constelação de questões que se constituem como problemas e desafios de uma determinada época (MEUCCI, 2006). Trata-se, assim, de construir uma sociologia de uma idéia tão cara ao debate intelectual contemporâneo para que então possamos, nas palavras lúcidas de Sérgio Buarque de Holanda, "reconhecer o passado para libertar-se dele". Ou seja, conhecer o passado para tentarmos escapar aos dilemas do presente, afinal de contas há uma história das relações entre natureza e sociedade (que nos conta muito da relação dos homens entre si) que ainda pesa sobre nossos ombros. 


\section{REFERÊNCIAS}

CANDID0, Antonio. Formação da literatura brasileira: momentos decisivos. 5. ed. Belo Horizonte: Itatiaia, 1975.

. Literatura e sociedade. 8. ed. São Paulo: Publifolha, 2000. (Grandes nomes do pensamento brasileiro).

- Os parceiros do Rio Bonito: estudo sobre o caipira paulista e a transformação dos seus meios de vida. 9. ed. São Paulo: Ed. 34, 2001.

DIAS, Maria 0. L. S. Sérgio Buarque de Holanda, Historiador. In: HOLANDA, Sérgio B. Sérgio Buarque de Holanda. São Paulo: Ática, 1985. (Coleção Grandes Cientistas Sociais, v. 51).

EISENSTADT, S. N. Multiple modernities. Daedalus, Cambridge, v. 129, n. 1, p. $1-29,2000$.

FERNANDES, Florestan. A sociologia no Brasil: contribuição para o estudo de sua formação e desenvolvimento. Petrópolis: Vozes, 1977.

FERREIRA, Antonio C. A epopéia bandeirante: letrados, instituições, invenção histórica (1870-1914). São Paulo: UNESP, 2002.

FERREIRA, Leila C. Idéias para uma sociologia da questão ambiental no Brasil. São Paulo: Annablume, 2006.

FRANCO, Maria S. C. Prosa com os parceiros do Rio Bonito. In: D'INCAO, MARIAA.; SCARABÔTOLO, Eloísa F. Dentro do texto, dentro da vida: ensaios sobre Antonio Candido. São Paulo: Cia das Letras: Instituto Moreira Salles, 1992.

HOLANDA, Sérgio Buarque. Caminhos e fronteiras. 3. ed. São Paulo: Cia das Letras, 1994. (1ª Edição: 1957).

IANNI, Otávio. Sociologia da sociologia. São Paulo: Ática, 1989.

MEUCCI, Simone. Gilberto Freyre e a Sociologia no Brasil: da sistematização à constituição do campo científico. Tese (Doutorado em Sociologia)- Instituto de Filosofia e Ciências Humanas, UNICAMP, Campinas, 2006.

ORTIZ, Renato. Da modernidade incompleta à modernidade-mundo. Idéias, v. 5, n. 1-2, 1999.

SOUZA, Jessé. A modernização seletiva: uma reinterpretação do dilema brasileiro. Brasília: Editora da Universidade de Brasília, 2000. 
TAVOLARO, Sergio B. F. À sombra do mato virgem: natureza e modernidade numa leitura sociológica brasileira. Ambiente e Sociedade, Campinas, v. 11, n. 2, 2008.

Existe uma modernidade brasileira: reflexões em torno de um dilema sociológico brasileiro. Revista Brasileira de Ciências Sociais, São Paulo, v. 20, n. 59, out. 2005.

TRINDADE, Nísia L. Um sertão chamado Brasil: intelectuais e representação geográfica da identidade nacional. Rio de Janeiro: Revan, 1999.

WEGNER, Robert. A conquista do oeste: a fronteira na obra de Sérgio Buarque de Holanda. Belo Horizonte: UFMG, 2000.

WITTROCK, Björn. Modernity: one, none, or many? European origins and modernity as a global condition. Daedalus, Cambridge, v. 129, n. 1, 2000. 